\title{
Multiband Low Profile Printed Monopole Antenna for Future 5G Wireless Application with DGS
}

\author{
Samineh Sarbazi Golazari* \\ Faculty of Engineering \\ South Tehran Branch, Islamic Azad \\ University \\ Tehran, Iran \\ S_S.GLZ@IEEE.org
}

\author{
Neda Rojhani \\ Department of Information \\ Engineering \\ University of Florence \\ Florence, Italy \\ Neda.rojhani@unifi.it
}

\author{
Nasrin Amiri \\ Department of Electrical and \\ Computer Engineering \\ Tarbiat Modares University \\ Tehran, Iran \\ N_amiri@modares.ac.ir
}

\begin{abstract}
A design and simulation of a low profile printed monopole antenna, which works at three different band for fifth generation (5G) of wireless application, is introduced in this paper. The designed antenna can achieve triple band performance to simultaneously cover the $13.6 \mathrm{GHz}, 22.12 \mathrm{GHz}$ and $28 \mathrm{GHz}$ frequency, which are three of the candidate frequencies for the next generation of wireless communications, with return loss of -

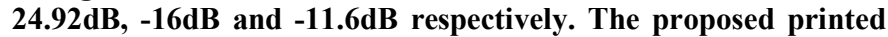
monopole antenna has a novel compact structure which consists of a mushroom-shape of patch where printed on the Rogers5880 substrate with a thickness of $1.4 \mathrm{~mm}$ and dimensions of $8.5 \times 10$ $\mathbf{m m}^{2}$ and a step transition line feeding which its position and configuration has been intentionally calculated for optimized matching. To decrease the interference between the $5 \mathrm{G}$ system and other applications, the ground of the structure is modified and defected to create two notched bands of $15-21.6 \mathrm{GHz}$ and $22.5-$ 24.5GHz. In addition, although the main polarization of this antenna is linearly polarized (LP), it radiates circularly polarized (CP) in the center frequency of $30.8 \mathrm{GHz}$. In this paper geometry of the antenna and various parameters such as radiation pattern plot, return loss plot, VSWR plot and axial ratio plot are presented and discussed.
\end{abstract}

Keywords-printed antenna; 5G; DGS; multiband; return loss; VSWR

\section{INTRODUCTION}

Emerging the next generation of wireless communication, which known as fifth generation $(5 \mathrm{G})$, is demanding antennas with numerous features such as wide impedance bandwidth, good radiation features, multiband operation, naive construction and low cost. Printed antennas can afford these requirements by some adjustments in the basic structure of these antennas like using the defected ground structure techniques (DGS), electromagnetic band gap structure (EBG) and other techniques[1]. However, the radiation pattern of these antennas are linear (LP) generally. As well as this, they radiate circularly polarized (CP) radiation wave endeavoring. The $(\mathrm{CP})$ antennas are employed in different type of applications such as satellite, sensor systems, radar, radio frequency identification (RFID) and navigation [2]. Greatly developments will be occurred in the applications of printed monopole antenna if it can generate the (LP) and (CP) radiation waves simultaneously.

In this paper, a novel structure of multiband printed monopole antenna with (CP) and (LP) simultaneously with the two notched band duo to reduce the interference with the $5 \mathrm{G}$ system and other applications is presented. The performance of the proposed antenna is analyzed and simulated by full-wave EM simulator CST MWS [3].

\section{ANTENNA DESIGN AND GEOMETERY}

The proposed antenna consists of four main parts: ground, substrate, feed line and the radiation element which has a mushroom shape.

The schematic configurations of top view of proposed printed monopole antenna is shown in Fig. 1 and the dimensions of parameter are listed in table. I in millimeter.

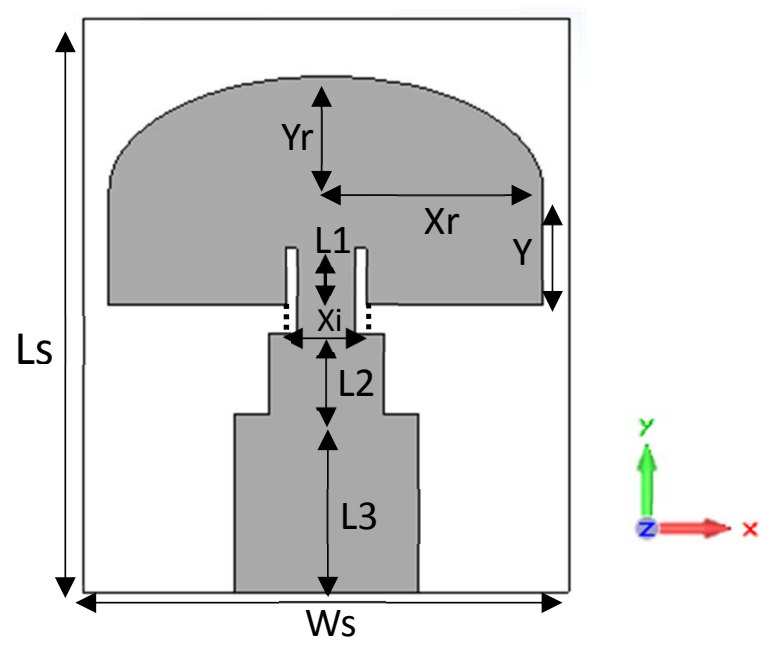

Fig. 1. Geometry of proposed antenna 
Table. I. dimensions of proposed antenna in $\mathrm{mm}$

\begin{tabular}{|c|c|c|c|}
\hline Parameter & Value & PARAMETER & VALUE \\
\hline L1 & 1 & Xr & 3.8 \\
\hline L2 & 1.5 & Yr & 2 \\
\hline L3 & 3.2 & Xi & 1.4 \\
\hline LS & 10 & Y & 2 \\
\hline
\end{tabular}

The prototype antenna is printed on an $8.5 \times 10 \mathrm{~mm}^{2}(\mathrm{Ws} \times \mathrm{Ls})$ Rogers RT5880 of $1.4 \mathrm{~mm}$ thickness, dielectric $\varepsilon_{\mathrm{r}}=2.2$. The Fig.2. Shows the back view of proposed antenna along with conventional ground plane.

\section{RESULTS AND DISCUSSION}

In this part the dual notched band printed monopole antenna with different parameters is simulated. As well as this, the parameters of the antenna are calculated by changing one parameter at a time and fixing the others. This part divided to three main sections: A. full band design and improving the bandwidth, B. notch band design, results of radiation features.

\section{A. Full band design and improving the bandwidth}

In this part of research, a study on the variation of $S_{11}$ parameters and bandwidth with conventional ground plane for different value of dimensions of Ws has been done to achieve the best matching and bandwidth at the interested frequency. Fig. 3. Shows the result of the study.
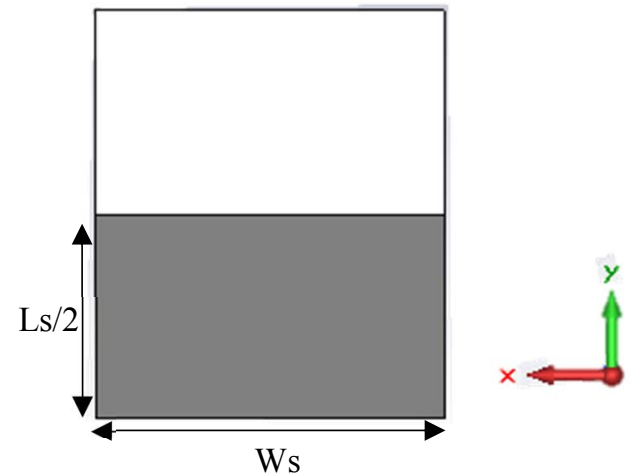

Fig. 2. Back view of proposed antenna

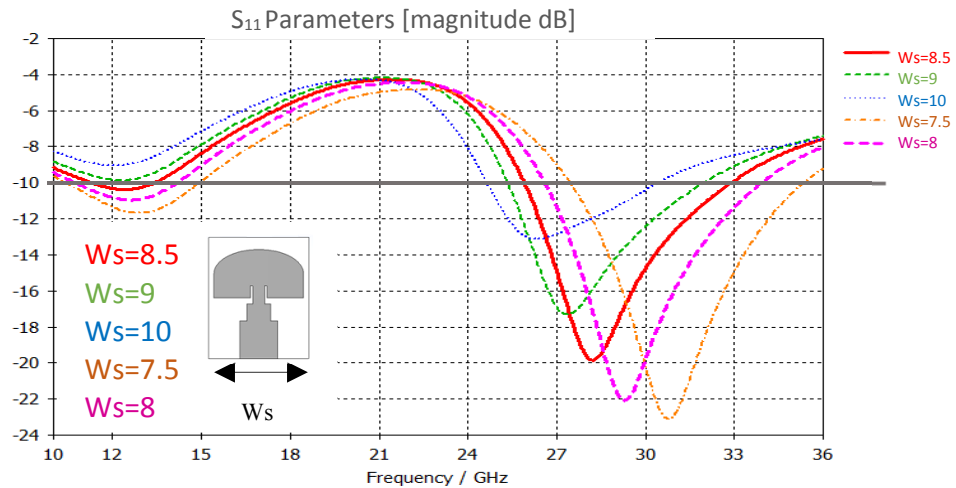

Fig. 3. Comparison of simulated return loss characteristic's for different values of Ws $[\mathrm{mm}]$
It is obvious from Fig. 3 that for value of $8.5 \mathrm{~mm}$ for Ws the best value of impedance matching with $\left|\mathrm{S}_{11}\right|$ less than $-10 \mathrm{~dB}$ at desirable frequency for $5 \mathrm{G}$ applications occurred.

\section{B. Notch band design}

In this section the main purposes are two. One of them is to create and enhance the resonant frequencies at two different band $(\mathrm{Ku}$ and $\mathrm{K})$ additional $\mathrm{Ka}$ band which achieve in last section and another one is to create two band notch to decrease the interference between the $5 \mathrm{G}$ system and other applications which work at other band.

For achieving to improve the bandwidth of these kinds of antennas modifying the ground plane structure methods like DGS can be employed [4]. Moreover this technique acts as filter and it can create a band stop [5]. The results of the using the different shape of defected ground structure (DGS) as an improvement in frequency bandwidth shows in Fig. 4. And the result of return loss characteristics for different value of $\mathrm{Ld}$ which lead to create band notches is shown in Fig. 5.

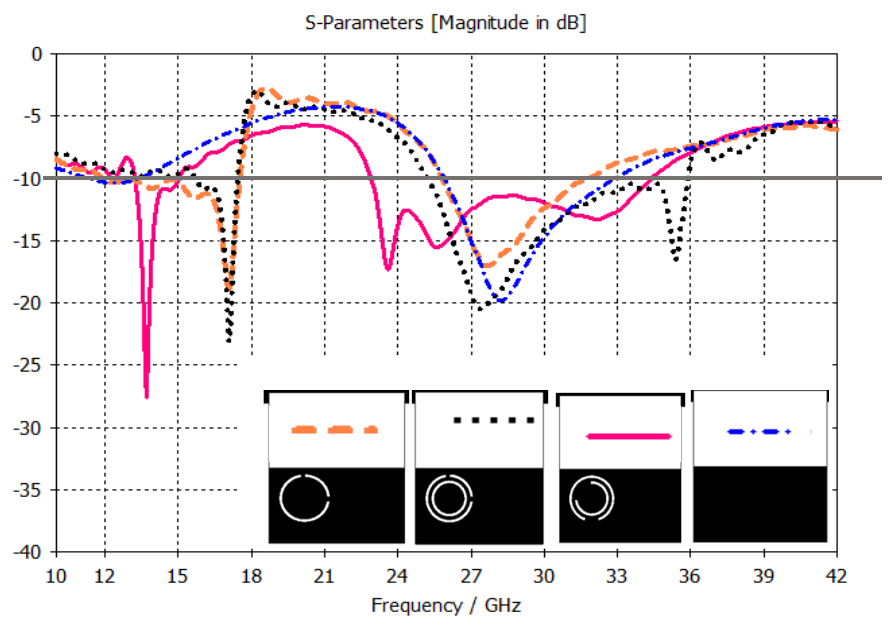

Fig. 4. Comparison of simulated return loss characteristics for different DGS

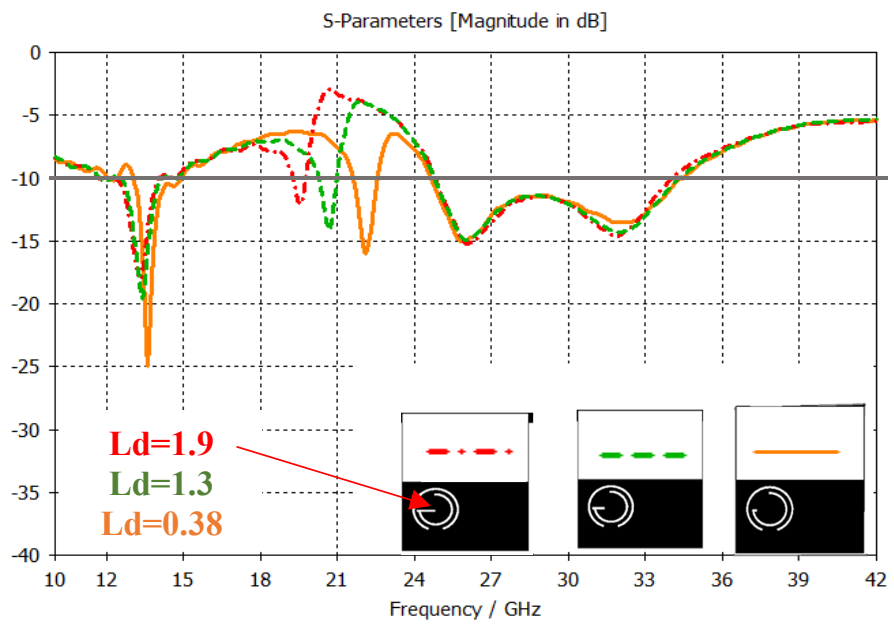

Fig. 5. Simulated return loss characteristics of the antenna for different value of $\mathrm{Ld}[\mathrm{mm}]$ 
As can be clearly seen from Fig.5, as Ld is reduce the resonance frequency at $\mathrm{K}$ band shift. According to Fig.5 The best result for desirable purpose belongs to the antenna with $\mathrm{Ld}=0.38 \mathrm{~mm}$, which leads to the designed antenna resonant at three different resonance at three different band and the band notches which create two band stop , $15-21.5 \mathrm{GHz}$ and $22.5-24.5 \mathrm{GHz}$. The Fig. 6 shows the VSWR of this antenna.

\section{Results of radiation features}

The designed printed monopole antenna provides $4.07 \mathrm{~dB}$ and $3.1 \mathrm{~dB}$ gain at $22.13 \mathrm{GHz}$ and $28 \mathrm{GHz}$ resonance frequency respectively. The simulated radiation pattern at resonance frequencies and axial ratio (AR) are shown in Fig.7 and Fig.8 respectively.

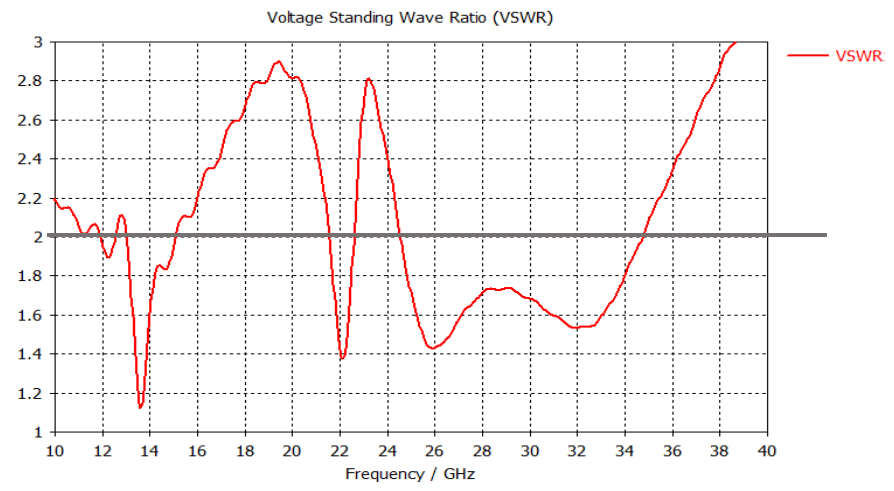

Fig.6. VSWR of proposed antenna
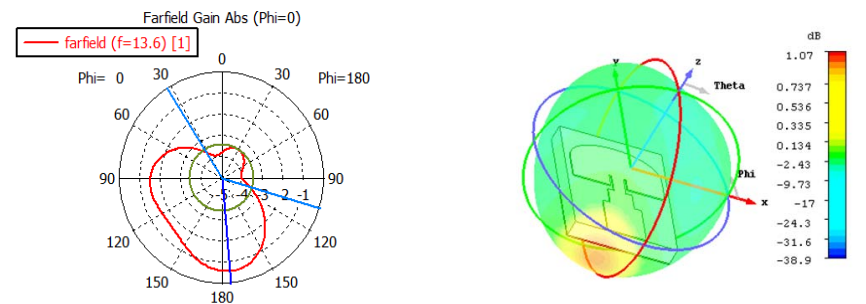

(a)
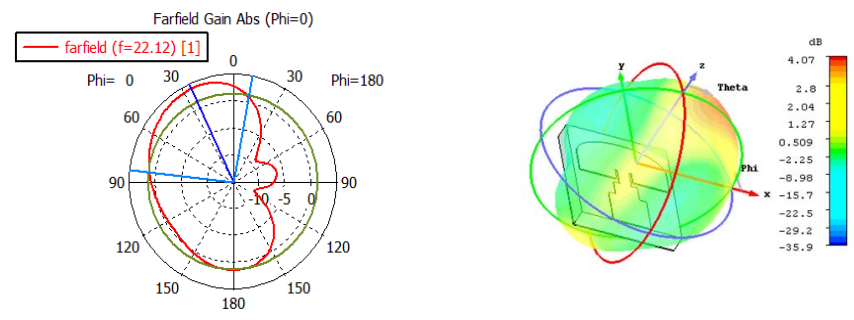

Theta / Degree vs. dB

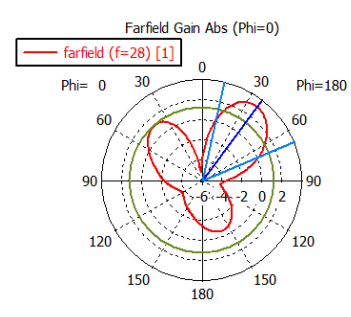

Theta / Degree vs. dB

Fig.7. 3D and 2D radiation pattern of proposed antenna at (a) $13.6 \mathrm{GHz}$ (b) $22.12 \mathrm{GHz}$ and (c) $28 \mathrm{GHz}$

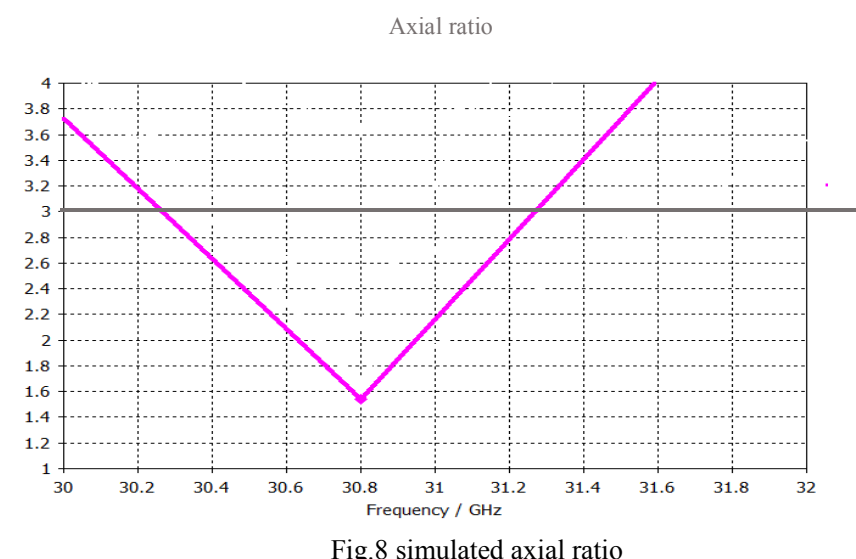

Fig. 8. Shows the simulated axial ratio of purposed antenna. Most of the printed antennas work at linear polarization. In this work by employing the DGS technique and calculating the best value of $\mathrm{Ld}$, the antenna works at two linear and circular polarization simultaneously at some part of $\mathrm{Ku}$ band. The bandwidth of circular polarization is from $30.26 \mathrm{GHz}$ to $31.27 \mathrm{GHz}$ that provides $1.01 \mathrm{GHz}$ circular polarization.

\section{CONCLUTIOC}

In this article, the design of a new multiband printed monopole antenna with the size of $8.5 \times 10 \mathrm{~mm}^{2}$ was presented. The good impedance matching (less than $-10 \mathrm{~dB}$ in $\mathrm{S}_{11}$ parameter) can be achieved over the three desire bands which consist $\mathrm{Ka}, \mathrm{K}$ and $\mathrm{Ku}$ band. The impedance bandwidth of proposed antenna with center frequency of $13.6 \mathrm{GHz}, 22.12 \mathrm{GHz}$ and $28 \mathrm{GHZ}$ are $13.68 \%, 4.52 \%$ and $33.72 \%$ respectively. Moreover dual band notches in designed antenna lead to reduce the interference

(b) 
between the $5 \mathrm{G}$ system and other applications. It is noted that the purposed antenna works at two different polarization (LP and CP) simultaneously. The purposed design illustrates advantages over the published works and it is very striking for 5G Wi-Fi applications along with other application duo to multiband.

\section{REFERENCES}

[1] Rupali T. Lalpotu; T. D. Biradar; Sanjay Thakur, "Improvement of bandwidth in printed monopole antenna by modified ground structures", International Conference on Global Trends in Signal Processing, Information Computing and Communication (ICGTSPICC) 2016.

[2] Z. N. Chen, M. J. Ammann, M. Y. W. Chia, andT. S. p. See, “Annular planar monopole antennas', Inst. Elect. Eng. Proc.-Microw. Antennas Propag.,vol. 149, No 4, pp 200 - 203, Aug. 2002.

[3] CST-Computer Simulation Technology, Documentation, Available online at: http://www.cst.com

[4] Weng, L. H., Y.-C. Guo, X.-W. Shi, and X.-Q. Chen, "An overview on defected ground struc-ture", Progress In Electromagnetics Research B, Vol. 7, 173, 2008.

[5] A. Znand, K. Shambavi, Z. C. Alex, " design of band pass filter with circular defected ground structure for UWB applications', ICCCI, 2014. 